\title{
Des pratiques dignes de confiance
}

Écrit par : Robin Davis,L'Observateur de l'OCDE

Dernière mise à jour : 12 décembre 2017

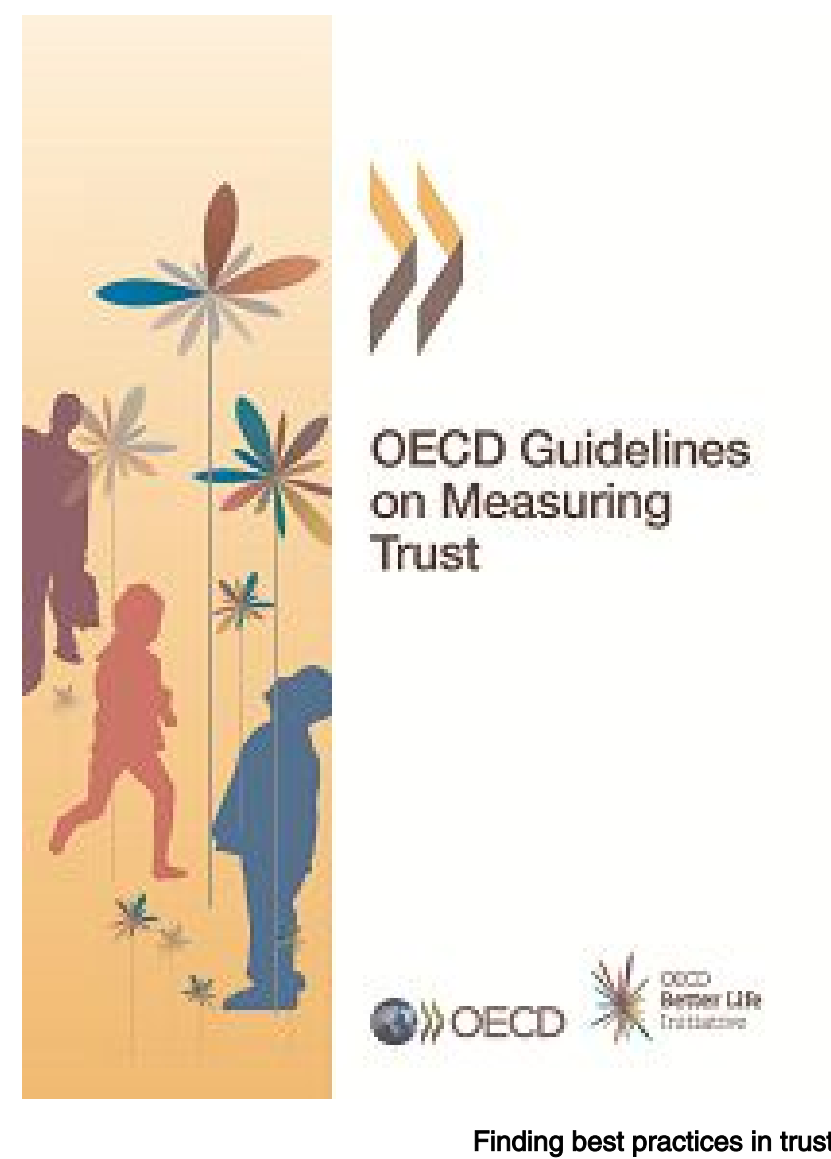

"Aime chacun, fie-toi à peu, ne fais tort à personne " : le conseil de William Shakespeare dans Tout est bien qui finit bien est toujours valable aujourd'hui. Après la crise financière de 2008, il semblerait que cette recommandation, en particulier sur la confiance, ait été suivie. Les pouvoirs publics et les institutions économiques ont perdu la confiance des citoyens. En conséquence, beaucoup d'institutions et de pays de l'OCDE font désormais de la mesure de la confiance, aussi difficile à conquérir que facile à perdre, une priorité. Comment quantifier avec exactitude et acuité le degré de confiance qui règne entre 
deux personnes ou entre une personne et une institution ? C'est justement ce qu'ont entrepris de faire les Lignes directrices de l'OCDE sur la mesure de la confiance.

Il est possible d'évaluer la confiance dans une grande diversité de domaines mais nous nous intéresserons tout particulièrement à la confiance interpersonnelle. Celle-ci peut être générale, quand elle s'applique aux inconnus, ou limitée, quand elle concerne des personnes qui se connaissent. Par exemple, facteur et employés de supermarché appartiennent à la première catégorie, tandis que collègues et amis relèvent de la deuxième.

Notons que les résultats des évaluations de la confiance donnent lieu à des initiatives qui dérivent le plus souvent de questions sur la confiance interpersonnelle, telles que : "Selon vous, la plupart des gens sont-ils dignes de confiance ou faut-il faire preuve de méfiance dans nos rapports aux autres ? " Les cinq premières questions des enquêtes sur la mesure de la confiance qui sont menées aux fins de l'élaboration des politiques et de la comparabilité internationale devraient toujours se concentrer sur la confiance interpersonnelle.

De telles stratégies et lignes directrices contribuent à fournir des données de meilleure qualité sur la confiance. De ces données découlent des politiques meilleures et, espérons-le, des vies meilleures, à l'image de la célèbre formule de Shakespeare : tout est bien qui finit bien.

@L'Observateur de l'OCDE, nº 312 T4 2017

\section{Références}

OCDE (2017), OECD Guidelines on Measuring Trust, Éditions OCDE, Paris. http:// dx.doi.org/http://dx.doi.org/10.1787/9789264278219-en 